\title{
Clinicopathologic features, management and outcome of ten cases of gastrointestinal stromal tumors
}

\author{
Md. Nazmul Hoque ${ }^{1}$, Samiron Kumar Mondal², Md. Mohsin Kabir ${ }^{3}$, Indrejit Kumar Datta ${ }^{1}$, \\ M Golam Azam¹, Md. Abdullah Al Mamoon', Shireen Ahmed ${ }^{1}$ \\ ${ }^{1}$ Department of Gastrointestinal, Hepatobilliary \& Pancreatic Disorders, Bangladesh Institute of \\ Research and Rehabilitation for Diabetes, Endocrine and Metabolic Disorders (BIRDEM), Dhaka, \\ Bangladesh, ${ }^{2}$ Department of Surgery, BIRDEM, Dhaka, Bangladesh, ${ }^{3}$ Department of Gastroenterology, \\ BRB Gastroliver Hospital, Dhaka, Bangladesh
}

\begin{abstract}
Background and objectives: Gastrointestinal stromal tumor (GISTs) is an uncommon and rare disease in Bangladesh. Our aims were to describe socio-demographic characteristics, clinical presentations, anatomical location, morphological variation, treatment and outcome of GIST in ten cases.

Methods: This study included consecutive ten cases of GISTs diagnosed and treated in two tertiary level hospitals in Dhaka, Bangladesh from 2013 to 2016. Patients' socio-demographic characteristics, clinical presentations, anatomical location, histological types, presence of CD117 markers were determined. Outcome of the treatment by surgical intervention and imatinib mesylate $(400 \mathrm{mg} /$ day) were evalauted.

Results: Total 10 patients were included in the study. Among them 6 were male and 4 were female. The age range was 32-74 years. Abdominal pain, haematemesis, melaena, haematochezia and anaemia were the most common presentation. One patient had dysphagia and another had features of subacute intestinal obstruction. Five patients had GIST in the stomach (50\%), two had in colon and one in esophagus, duodenum and ileum respectively. CD 117 was positive in 8 cases, majority had spindly type cell with low mitotic figure. Imatinib therapy was given in all the cases except two patients. Disease recurrence in the form liver metastasis was found in two cases and both died. Disease free survival for more than 2 years was observed in 4 cases.

Conclusion: Haematemesis and melaena were common presentation of GISTs. Stomach was the most common site for GISTs and majority had spindle type of cells and positive CD117 marker. Surgical intervention and imatinib therapy was found effective.
\end{abstract}

IMC J Med Sci 2017; 11(2): 45-49

\section{Introduction}

Gastrointestinal stromal tumors (GISTs) are the mesenchymal tumors of the gastrointestinal tract (GI) and account for less than 1\% of GI tumors [1]. About $60 \%-70 \%$ GIST arises from the stomach and the rest are from small intestine (20\% to $30 \%)$, colon and rectum (5\%), and esophagus $(<5 \%)$ [2]. A small number of stromal tumors may originate from outside the gastrointestinal tract. These are designated as extragastrointestinal stromal tumors (EGISTs) [3].

Historically, these lesions were classified as leiomyomas or leiomyosarcomas because they possessed smooth muscle features. With the advent of immunohistochemical staining techniques GISTs now are recognized as a distinct group of mesenchymal tumors. GISTs express c-kit protein also known as CD117, and is considered a specific

\footnotetext{
Address for Correspondence:

Dr. Md. Nazmul Hoque, Consultant and Head, Department of GHPD, Ibrahim Medical College \& BIRDEM General Hospital, 122 Kazi Nazrul Islam Avenue, Dhaka, Bangladesh.Email: alifbd@gmail.com
} 
marker that differentiates GIST from other mesenchymal tumors such as leiomyomas [4].

The most common clinical manifestation for symptomatic GIST is pain in abdomen and GI bleeding from mucosal ulceration [5]. Other presentations include mass in the abdomen or intestinal obstruction. Endoscopy and colonoscopy clearly delineate the site and macroscopic appearance. However, ultrasonography (USG) and computerized tomographic (CT) scan are useful to determine the location of tumor in the gastric or intestinal wall [6].

Tumors less than $2 \mathrm{~cm}$ in diameter with a mitotic rate of $<5 / 50 \mathrm{HPF}$ (high power field) have been shown to have lower risk of recurrence than larger tumors. All GIST tumors should be considered to have malignant potential [7]. At present, surgery remains the mainstay of treatment for GIST. Recently, imatinib mesylate has been introduced as an adjunct therapy for metastatic disease, for non resectable tumor and for prevention of recurrence [5]. In this report, we describe the socio-demographic characteristics, clinical presentations, anatomical location, investigations, morphological variation, treatment and outcome of GIST encountered over four years period at two tertiary care hospitals.

\section{Methods}

All the patients diagnosed with GISTs from 2013 to 2016 at two tertiary care of hospitals (BIRDEM General Hospital and Gastroliver Hospital) of Dhaka city were included in the study. GIST cases were analyzed for age, sex, clinical features, tumor location, size, histological characteristics and CD117 marker. Types of surgery, post operative event, outcome of imatinib therapy, disease recurrence, recurrence site and survival rate were also analyzed. Mitotic figure defined as number of mitosis per $50 \mathrm{HPF}$ (high power field). Disease recurrence means local recurrence or distant metastasis. GIST cases with inconclusive histological findings during the study period were excluded. Long term follow up at intervals were done by clinical examination, routine blood test and abdominal USG.
Results

A total of ten cases of GIST were included in the study for analysis. Six of them were male, 4 were female. Their age ranged from 32-74 years. Five patients presented with GI bleeding in the form of haematemesis, melaena and haematochezia, three patients had abdominal pain, two patients had anemia, one patient had dysphagia and one had features of subacute intestinal obstruction (Table I).

Out of ten cases, 5 (50\%) tumors were present in the stomach. Among stomach GIST, two involved the fundus, two were in antrum and one in mid body near the greater curvature. Two patients had GIST in the caecum. Detail distribution of GISTs is shown in Table-1. Partial gastrectomy and gastrojejunostomy (Billroth II) were done in three cases and fundectomy in two cases by using stapler. Right hemicolectomy and ileo transverse anastomosis was done in two cases. In case of ileal GIST, resection and anastomosis was done and duodenotomy and enucleation was done to manage the duodenal GIST (Table 1). Only two patients experienced diarrhea during post operative period.

Average sizes of the GIST were $4.2 \times 4.8 \mathrm{~cm}$. Histological examination revealed spindle type of cell in $80 \%$ cases and $20 \%$ cases had mixed type of cell (Table 2). CD117 was positive in $80 \%$ cases, two patients were negative for CD117 but histologically both were diagnosed as GIST. Average mitotic figure was 1.4/50 HPF. Mitotic figure were absent in three cases. All patients were advised imatinib therapy. Eight out of ten patients took imatinib for 6 months to 3 years (Table 2). Disease recurrence in the form of liver metastasis was found in two cases despite of taking imatinib for more than one year. These two patients had large size GIST and mitotic figures were more than that of other cases and both expired during this follow up time due to liver metastasis No metastasis or recurrence was observed in four cases after 2-3 years of follow up. No metastasis or recurrence was observed in four cases after 2-3 years of follow up. Detail recurrence and disease status of all the cases in follow up after a range of period (6 month to 3 years) are shown in Table-2. 
Table-1: Salient clinical features, anatomical sites of GISTs and types of surgical intervention $(n=10)$

\begin{tabular}{|c|c|c|c|c|c|c|}
\hline Case & Age & Sex & $\begin{array}{c}\text { Clinical } \\
\text { presentation }\end{array}$ & $\begin{array}{c}\text { Anatomical site of } \\
\text { GIST }\end{array}$ & Type of surgery & $\begin{array}{l}\text { Post operative } \\
\text { complications }\end{array}$ \\
\hline 1 & 55 & $\mathrm{M}$ & $\begin{array}{l}\text { Haematemesis \& } \\
\text { melaena }\end{array}$ & $\begin{array}{l}\text { Stomach - antral } \\
\text { region }\end{array}$ & Billroth II & None \\
\hline 2 & 65 & $\mathrm{~F}$ & Haematochezia & Caecum & $\begin{array}{l}\text { Right hemicolectomy } \\
\text { and anastomosis }\end{array}$ & Diarrhea \\
\hline 3 & 50 & M & $\begin{array}{l}\text { Haematemesis \& } \\
\text { melaena }\end{array}$ & $\begin{array}{l}\text { Stomach - antral } \\
\text { region }\end{array}$ & Billroth II & None \\
\hline 4 & 32 & M & $\begin{array}{l}\text { Odynophagia \& } \\
\text { dysphagia }\end{array}$ & Upper esophagus & $\begin{array}{l}\text { Thoracotomy and GIST } \\
\text { enucleation }\end{array}$ & None \\
\hline 5 & 52 & $\mathrm{~F}$ & Anemia & Caecum & $\begin{array}{l}\text { Right hemicolectomy } \\
\text { and anastomosis }\end{array}$ & None \\
\hline 6 & 65 & M & $\begin{array}{l}\text { Abdominal pain, } \\
\text { Sub acute intestinal } \\
\text { obstruction \& } \\
\text { Abdominal lump }\end{array}$ & Terminal ileum & $\begin{array}{l}\text { Resection and } \\
\text { anastomosis }\end{array}$ & Diarrhea \\
\hline 7 & 74 & $\mathrm{~F}$ & $\begin{array}{l}\text { Haematemesis \& } \\
\text { melaena }\end{array}$ & Stomach-fundus & Fundectomy & None \\
\hline 8 & 48 & M & $\begin{array}{l}\text { Abdominal pain \& } \\
\text { anemia }\end{array}$ & duodenum & $\begin{array}{l}\text { Duodenotomy and } \\
\text { excision }\end{array}$ & None \\
\hline 9 & 45 & $\mathrm{~F}$ & $\begin{array}{l}\text { Abdominal pain \& } \\
\text { anaemia }\end{array}$ & Stomach-fundus & Fundectomy & None \\
\hline 10 & 56 & M & $\begin{array}{l}\text { Haematemesis \& } \\
\text { melaena }\end{array}$ & $\begin{array}{l}\text { Stomach - near the } \\
\text { greater curvature }\end{array}$ & Billroth II & None \\
\hline
\end{tabular}

Note: Billroth II - Partial gastrectomy with gastrojejunostomy.

Table-2: Histological types, duration of imatinib therapy and recurrence rate of diseases among the study population.

\begin{tabular}{|c|c|c|c|c|c|c|c|c|}
\hline \multirow[b]{2}{*}{ Case } & \multirow[b]{2}{*}{$\begin{array}{l}\text { Size } \\
(\mathbf{c m})\end{array}$} & \multicolumn{2}{|c|}{ Microscopic appearance } & \multirow[b]{2}{*}{ CD 117} & \multirow{2}{*}{$\begin{array}{l}\text { Duration of } \\
\text { Imatinib } \\
\text { therapy (Yr) }\end{array}$} & \multirow[b]{2}{*}{ Recurrence } & \multirow[b]{2}{*}{$\begin{array}{l}\text { Disease } \\
\text { free }\end{array}$} & \multirow[b]{2}{*}{ Death } \\
\hline & & $\begin{array}{l}\text { Cell } \\
\text { type }\end{array}$ & $\begin{array}{c}\text { Mitotic } \\
\text { figure/50 HPF }\end{array}$ & & & & & \\
\hline 1 & $3 \times 4$ & spindle & 2 & Positive & 2 & no & yes & no \\
\hline 2 & $5 \times 6$ & Mixed & 3 & Positive & 1 & Yes* & no & Yes** \\
\hline 3 & $4 \times 3$ & Spindle & 1 & Positive & 2 & no & yes & no \\
\hline 4 & $4 \times 6$ & Spindle & 0 & Positive & $(-)$ & no & yes & no \\
\hline 5 & $4 \times 5$ & Spindle & 0 & Positive & 3 & no & yes & no \\
\hline 6 & $7 \times 6$ & Spindle & 0 & Positive & 1 & no & yes & no \\
\hline 7 & $4 \times 5$ & spindle & 2 & Positive & 0.5 & no & yes & no \\
\hline 8 & $4 \times 5$ & spindle & 2 & Positive & 3 & no & yes & no \\
\hline 9 & $3 \times 3$ & Mixed & 1 & Negative & $(-)$ & no & yes & no \\
\hline 10 & $4 \times 5$ & spindle & 3 & Negative & 1 & Yes* & no & Yes*** \\
\hline
\end{tabular}

Note: Mixed: Spindle \& Epitheloid type; *indicates Metastasis in liver; **indicates death after 2.5 years following surgery; ***indicates death after 2 years following surgery; (-) did not receive imatinib therapy 
Discussion

GIST is a very uncommon and rare disease in Bangladesh. Few sporadic case reports of GIST among Bangladeshi patients were published in the literature [8]. GISTs are most common in adults between 50-60 years of age [9]. However, a case of jejunal GIST in a 38 year male patient has also been reported [5]. In our series, one patient had esophageal GIST aged 32 years and presented with dysphagia. The oldest case in these series was a 74 years lady. The common presenting feature in this study were GI bleeding. Gross GI bleeding was present in $50 \%$ cases and $20 \%$ cases had occult bleeding. Abdominal pain, abdominal distension, abdominal lump and dysphagia were also present. Similar presentations were described in other studies $[10,11]$.

The vast majority of GISTs (60 to $70 \%$ ) arise in the stomach, with $20-30 \%$ originating in the small intestine and the remainder $10 \%$ occurring in the esophagus, colon and rectum [12]. In our series, stomach was involved in $50 \%$ cases and $20 \%$ were in the colon. Most of the GISTs were small and asymptomatic and were discovered incidentally during evaluation for unrelated problems. When the lesion grows over $2 \mathrm{~cm}$ in size, ulceration may occur and symptoms like epigastric pain and gastrointestinal bleeding become more common at that time. Spontaneous rupture of large mass into gastric lumen has also been reported [13]. The average size of the lesion in our cases was $4.2 \times 4.8 \mathrm{~cm}$.

Histologically GIST's may be spindle or epithelioid type. Spindle cell GISTS are more common. Histologically, most cases fall into one of the following three categories, spindle cell type $-70 \%$, epitheliod type - $20 \%$, mixed type $-10 \%$ [14]. In our series, $80 \%$ cases were spindle type; remaining $20 \%$ were defined as mixed variety. In general, GISTs with less than 1 mitotic figure per $50 \mathrm{HPF}$ are correlated with benign behavior. It has been reported that presence of 1-5 mitotic fegures per 10 HPFs suggest potential malignancy. A finding of more than 5 mitotic figures per $10 \mathrm{HPFs}$ indicates malignancy. A finding of more than 10 per 10 HPFs denotes high-grade malignancy [14].

About 10\% GISTs exhibit malignant behavior [15]. Prognostic factors include age, location staging, tumor size and mitotic activity. Esophageal and gastric GISTs have a better prognosis than intestinal GISTs. Size and mitosis are most useful predictors. In our series, the average mitotic figure was 1.4/50 HPF, and disease recurrence were found in two cases. These two patients had large tumor size and high mitotic figure (3/HPF).

In our study, $80 \%$ of tumors were positive for CD 117 marker. CD117 positivity (diffuse cytoplasmic staining with membranous accentuation) is seen nearly in all GISTs with spindle cell or epitheloid morphology, though less intensely in the latter. A small number of otherwise typical GISTs may be CD117 negative and immune-reactivity for CD117 is sometimes lost in metastatic cells [8].

Surgery, in the form of wide surgical resection, is the mainstay of therapy for non-metastatic GISTs. Laparoscopic surgery has been shown to be effective for removal of these tumors without the need of large incisions [16]. But in our series, all patient underwent laparotomy.

Imatinib mesylate was first approved by FDA in 2001 [17]. It is the first and only effective drug for treatment of GIST at present. According to the latest ASCO guidelines, recurrence free survival is increased in patients taking imatinib $400 \mathrm{mg} /$ day for one year of [5]. In our series, 2 patients did not receive imatinib but remained disease free during the follow up period. Disease recurrence was found in two cases even after taking imatinib.

In our study, common presentation of GIST was gastrointestinal bleeding and the common site of involvement was stomach. Histologically majority were positive for spindle type of cell and CD117 marker. Surgical intervention along with imatinib therapy was effective for disease free survival in most of the cases.

Conflict of interest: None declared.

\section{References}

1. Zhao X, Yue C. Gastrointestinal stromal tumor. J Gastrointest Oncol. 2012; 3: 189-208.

2. Miettinen M, Furlong M, Sarlomo-Rikala M, Burke A, Sobin LH, Lasota J. Gastrointestinal stromal tumors, intramural leiomyomas and 
leiomyosarcomas in the rectum and anus: a clinicopathologichistochemical and molecular genetic study of 144 cases. Am J Surg Path. 2001; 25(9): 1121-1133.

3. Reith JD, Goldblum JR, Lyles RH, Weiss SW. Extragastrointestinal (soft issue) stromal tumors: an analysis of 48 cases with emphasis on histologic perdictors of outcome. Mod Pathol. 2000; 13(5): 577- 585.

4. Miettinen M, Sarlomo-Rikala M, Lasota J. Gastrointestinal stromal tumors: recent advances in understanding of their biology. Hum Pathol. 1999; 30: 1213-1220.

5. Dhull AK, Kaushal V, Dhankar R, Atri R, Singh H, Marwah N. The inside mystery of jejunal gastrointestinal stromal tumor: A rare case report and review of literature. Case reports in Oncological Medicine 2011, Article ID 985242, 4 pages, 2011.

6. Isimbaldi G, Santangelo M, Cenacchi G, Cribiù FM, Claren R, Delpiano C, Spinelli M, et al. Gastrointestinal autonomic nerve tumor (plexosarcoma): report of a case with fine needle aspiration biopsy and histologic, immunocytochemical and ultrastructural study. Acta Cytol. 1998; 42: 1189-94.

7. Raut C, Dematteo R. Evidence-Guided Surgical Management of GIST: Beyond a simple case of benign and malignant. Ann Surg Onc. 2008; 15(5): 1542.

8. Maitra TK, Roy S, Mondol SK, Alam NA. Gastrointestinal stromal tumor: a case report. Birdem Med J. 2013; 3(1): 47-49.

9. Guy JC, Badran M, Omar A, Thomas JM, Judson IR, Fisher C, Moskovic EC. Malignant gastrointestinal stromal tumor: distribution, imaging features, and pattern of metastatic spread. Radiology. 2003; 226(2): 527-532.
10. Goettsch WG, Bos SD, Breekveldt PN, Casparie M, Herings RM, Hogendoorn PC. Incidence of gastrointestinal stromal tumours is underestimated: results of a nation-wide study. Eur J Cancer. 2005; 41: 2868-2872.

11. Miettinen M, Lasota J. Gastrointestinal stromal tumors (GISTs): definition, occurrence, pathology, differential diagnosis and molecular genetics. Pol J Pathol. 2003; 54: 3-24.

12. DeMatteo RP, Lewis JJ, Leung D, Mudan SS, Woodriff JM, Brennan MF. Two hundred gastro-intestinal stromal tumors: recurrence patterns and prognostic factors for survival. Ann Surg. 2000; 231: 51-58.

13. Mehta RM, Vayoth OS, John AK, Nandakumar RR, Dhar PS, Sudhindran S et al. Spontaneous rupture of giant gastric stromal tumor into gastric lumen. World Journal of Surgical Oncology. 2005; 3(11): 1477-1478.

14. Pidhorecky I, Cheney RT, Kraybill WG, Gibbs JF. Gastrointestinal stromal tumors: current diagnosis, biologic behavior, and management. Ann Surg Oncol. 2000; 7(9): 705-712.

15. Li SQ, O’Leary TJ, Buchner SB, Przygodzki RM, Sobin LH. Fine needle aspiration of gastrointestinal stromal tumors. Acta Cytol. 2001; 45: 9-17.

16. Nguyen SQ, Divino CM, Wang JL, Dikman SH. Laparoscopic management of gastrointestinal stromal tumors. Surg Endosc. 2006; 20(5): 713-6.

17. Van AT, Judson I, Verweij J, Stroobants S, Donato D, Paola E. et al. Safety and efficacy of imatinib in metastatic gastrointestinal stromal tumours: a phase I study. Lancet. 2001; 358: 1421-1423. 